\title{
Study on the Social and Economic Functions of Economic Law
}

\author{
Qi Jingyu \\ Chengdu Sichuan Winshare Vocational College, Sichuan 611330
}

Keywords: economic law, social and economic function

\begin{abstract}
Since the reform and opening up, China's economy has been developing continuously, and all the social undertakings have achieved remarkable achievements. In 2001, China formally joined WTO, which indicates that China will be more involved in the international trade, and with the development of market economy, China has seen considerable development. And related economic laws are the foundation to ensure the normal development of the economy, a relatively perfect and reasonable economic law can promote the development of the social economic function of long period, according to economic law analysis, development suggestions of China's economy.

Economy is the foundation for the development of a country, the development of the fundamental economy in China will affect all areas of society, only the steady development of economy can ensure the stability in the long period. The economic development needs to be within certain rules, only according to the objective law, which conforms to the trend of the development of the times in order to get the development of the economy. In this situation, the economic law comes into being, it can not only coordinate the various problems of the domestic market economy, but also can provide a strong theoretical basis for the China International Economic and trade exchanges, economic and social function of economic law can promote the economic development of our country, providing a strong guarantee for China's socialist construction[1].
\end{abstract}

\section{Overview of economic law}

Since the reform and opening up, the market economy has made considerable development in our country, the development of the market economy for the prosperity of China's economy has played a crucial role, while its development drawbacks are gradually revealed, need the relevant laws and regulations of the specification to be completely, development and integration of China's socialist cause.

On the economic law must first clear the concept of economic law in our country is not specific to a law is a general term for Chinese economic law, is based on the national and economic functions of government departments to exercise legal means to coordinate the activities of market economy, with the macro-control of China's socialist economic relations, is an important part of our country's legal system. Economic law is conducive to the healthy development of our market economy, the coordination of market economy activities, and the regulation of socialist commodity economic relations[2].

The essence of economic law in China for the country in accordance with the objective laws of economic development, the law as a means of macro-control measures and behavior of the socialist market economy, from the overall situation, from a strategic perspective to analyze, through the economic approach to coordination management of social and economic law.

The development of the country cannot do without economy, people's life more and more cannot do without economy, between country and country to trade, to the people's daily consumption, it comes down to different economic activities, the purpose of economic activity led to the results of economic activities is different, and the numerous economic activities need a a unified rule, but there are human factors, which requires a new rule under the state through macro-control means to ensure economic activities orderly harmony, to ensure the normal operation of economic activities, the state and the people's life and development can be guaranteed.

Economic law is an important part of the legal system of our country. All the economic activities 
of our country are within the jurisdiction of the economic law. The economic law is mainly aimed at the limitation and blindness of market regulation and the establishment of the market itself has the function of regulation, but it has some limitations, it is likely to cause social inequality, the widening gap between rich and poor, caused by social contradictions, which requires economic law in coordination, ensure the relative balance of the allocation of social resources. In addition, this is the nature of a socialist country based on China as a socialist country, the purpose of economic activity is not mercenary, to ensure the stability of people's lives happiness is our party's goal, and the implementation of economic law is the strong social economy, ensure social justice, maintain the legal protection of the national long period of stability.

\section{Social and economic functions of economic law}

As an important part of China's socialist legal system, economic law naturally has the basic functions of law. The basic functions of China's socialist law consist of three main categories. First, the guiding role of law. The law is enacted by the state, to ensure social fairness and stability provisions to the state machine as the background, has a certain political and social purpose; second, law has the integration of social resources, the state by law as the basic means to regulate social resources, reduce the gap between rich and poor, the practice of relative social fairness and the integration of resources, to ensure the fair justice; third, legal shaping function of culture, culture is the soul of a nation, our country has paid attention to the cultural construction, in order to ensure legal form of cultural heritage and carry forward the traditional culture of China is for the attention of China is shaping a way of national culture. In view of the economic law, in addition to the above three major functions, the specific social and economic functions can be divided into the following points[3].

The relationship between rights and obligations does not have to say, the rights and obligations are complementary, have rights and must fulfill obligations of economic law through the relevant provisions of the rights and obligations of the economic subjects in the market economy, the purpose of this provision is to reduce the gap between rich and poor, falling real macro-control policies, avoid disadvantages of the market self adjustment the increase in efficiency of market economic activities, thus promoting the development of economic activity and the stability of the market economy.

In today's era of rapid development, the value of information is very important, especially in the market economy, which is the economic subject first mastered the information, you can in the market first surfaced, in an invincible position in the market, therefore, information is of realistic meaning for market players.

The economic subject in the market through economic information to determine their economic behavior, enough information is conducive to the economic subject and judge the market situation and future trend of development, is conducive to economic decision-making, while economic law is a barometer of the market economy, to truly reflect the state of development of the market, guiding the behavior of people, provide the basis for the people economic activity.

The concept of transaction costs is the winner of the Nobel prize in economics, the interest rate, is mainly refers to the people in the economic activities for product search, access to information and the cost of customer service, the implementation of economic law to avoid the risks, which virtually eliminates the cost, which has become a necessary economic function the social and economic law.

The economic law to protect personal interests, regulate the behavior of economic agents in the market, to provide the necessary information for the consumer market, at the same time, to crack down on counterfeiting and fan Jia, required to provide true and reliable products, eliminating the need for consumers to handle customer service costs, the formation of the event of disputes, both sides can be coordinated in accordance with the relevant provisions of the economic law, to reduce unnecessary spending, but also improve the efficiency of market, let the market run with legal protection[4]. 


\section{Problems in the social and economic functions of economic law}

Since the third Plenary Session of the 11th CPC Central Committee, our country will focus all shifted to economic construction, but there are still some unresolved issues, in recent years, with the continuous development of the economy, more complex domestic and international economic situation, China's economic and legal issues have gradually emerged, for international, one of several developed countries the trade barriers is our export barriers, the domestic market economic development change rapidly, it brings challenges to the economic legal system of our country. Our country is still in the primary stage of socialism development, this stage has its own limitations, therefore, economic and legal system is not perfect is the times and social development, I believe that with the passage of time, the economic legal system of our country will be constantly improved, to provide strong legal guarantee for the economic development of china.

The law is formulated in order to protect the normal operation of the state and society, not only the law, but due to various internal and external factors, China's economic law has low operability, the development of a market economy and the international economic situation changes, study the economic law of our country are lagging behind the situation on the other hand; China's economic legislation situation is relatively simple, but the content is abstract, the actual operation is not high at present has become a major problem facing China's economic law.

Due to the abstraction of economic law content, resulting in the process of law enforcement and law enforcement subject confusion, in accordance with the law, the law enforcement main body is related to the economic problems of economic management departments and economic supervision and management organs, and in the actual law, both state organs, and some non economic management departments, and even the village will act as the economic law enforcement situation, enforcement of the main confusion of law enforcement and law enforcement is not in place the main confusion, the formulation and implementation of economic law is to ensure that the relative average allocation of social resources, to ensure social stability, and enforcement of the main confusion is exacerbated this situation, some departments and personnel in order to their own interests, in the process of law enforcement in violation of the law, not according to law, affect the rational allocation of resources and the fair competition in the market[5].

Economic law is an important part of China's socialist legal system, the formulation and implementation of all need supervision of the relevant departments, the supervision mechanism is not perfect cause problems during the implementation of the economic law, law enforcement leads to arbitrariness, no supervision under the jurisdiction of the case, although the government has the relevant legal supervision department, but in in the practice of law enforcement, supervision departments are not as many cases, that there is corruption in law enforcement economy, these problems will affect the healthy development of the socialist market economy.

\section{Strategies for social and economic function of economic law}

The improvement of the legal system is the basis for the stable development, and the continuous establishment and improvement of the economic legal system can effectively exert the social and economic functions of the economic law. From the economic and social function of economic law, and constantly improve the economic law is conducive to better solve the problem of people's livelihood, more reasonable allocation of market resources to promote the national macro-control means can be more fully applied to the market economy, realize the sustainable development of economy.

In addition, to constantly improve the legal supervision organization of the functions and responsibilities of law enforcement must be supervised mechanism of supervision, strengthen law enforcement and to strengthen law enforcement supervision, to ensure the scientificity and fairness, maintain fairness and justice society, to ensure the smooth development of social stability and economy. At the same time, to play the power of the masses to legal supervision, people's power is infinite, our party has always insisted to the masses from the masses of the mass line, which is connected with the masses of the blood, the masses are the historical development of the promoters, 
the supervision of the masses strength to some extent than the relevant supervision organizations that can effectively carry out supervision of the economic law enforcement, to ensure the fairness of law enforcement, maintaining social justice.

At present, China's social and economic situation, the law enforcement agencies according to law or not will directly affect the stability of the society, especially the economic law enforcement coordination related to economic development and market, law enforcement agencies must according to law in the process of law enforcement, clear terms of reference, and resolutely put an end to the law enforcement activities of any organization or individual without economic law enforcement, law enforcement agencies should proceed from the interests of the people, in accordance with the relevant economic laws and regulations, clearly the main law enforcement authority and responsibilities, and implement the relevant policies of economic laws and regulations, to ensure the legal basis for enforcement.

Local protectionism has always been a hindrance to the economic development of the country, and it is also a situation that the state has been severely combating but not eliminating it. Local protectionism refers to the place as the center, exclusion of foreign goods and services, adhere to the "homegrown", a behavior of local businesses and commodities. In the era of development today, still some areas of awareness is not high, the development of local enterprises and the sale of local goods, under the exclusion of foreign enterprises and commodity consciousness, this behavior will affect the development of national economy, is very irresponsible behavior, there is no distinguish between global and local relations, therefore at present, the economic law requirements, under the condition of market economy, to crack down on the local protectionism, to ensure the normal flow of goods and services, for the local protectionism in some areas resolutely banned, realize the market economic development advantages, ensure fair competition and development under market economy.

The improvement of legal consciousness is the basis for solving many problems of law. The improvement of people's legal consciousness can effectively promote the improvement and improvement of law, and also ensure the balance and fairness of social resources allocation. Through a variety of ways to enhance the legal consciousness of national people not only have a certain role in the economic field, for each field of the society will have a great benefit, can effectively promote the social stability and unity, alleviate social contradictions, improve people's well-being, at the same time, to enhance the comprehensive national strength will play a positive role. Improving the legal consciousness of the whole people will be conducive to fair and just market in the economic field, to maintain the order of the market economy, to the healthy development of the national economy, and to the national economic construction[6].

\section{Conclusions}

Economy is the lifeblood of national development, national independence and prosperity, economic development is the top priority of construction in China at present, while the economic law is a legal guarantee for an integral part of the development of economy, the economic law with its unique social and economic functions of market regulation and stability, continue to play its due role, although the the construction of China's economic law there are still some problems, but this is the inevitable development of the society and the times, believe in the future development, all the problems will be smoothly done or easily solved, the development of China's economy will be more prosperous, to provide a powerful guarantee for the development of China's other socialist undertakings.

\section{References}

[1] Wang Q X, Guan B. A Study on the Relationship Between Economic Law and Social Law[J]. Modern Law Science, 2003.

[2] Michael Perelman. Political Economists and the English Poor Laws: A Historical Study of the 
Influence of Classical Economics on the Formation of Social Welfare Policy [J]. Medical History, 1980, 24(2):221-221.

[3] Jiang W A, Sheng L I. Legal Protection of Whole Social Interest__Analysis of the Foundation Domain of Economic Law [J]. Law Science, 2005.

[4] Shi J. Openness and Knowledge Sharing of Economics, Sociology, Law and Politics: A Comparative Study on Citations of Chinese Social Science Journals [J]. Journal of Zhejiang University, 2012, 51(2):488-514.

[5] Chen N X. A study on the Urban Agglomeration Economy and Social Development and Their Legal Safeguard under the Economic Law in China [J]. Journal of Kunming University of Science \& Technology, 2008.

[6] Yue C S. Theoretical Innovations in the Development of Chinese Economic Law Jurisprudence during the Latest Thirty Years and Their Contributions [J]. Journal of Chongqing University, 2008.

Author: Qi Jingyu, female (January 1982), the Han nationality, Ru'nan County of Henan Province, Sichuan Wenxuan Career Academy, master, lecturer, research direction: Civil and commercial law and economic law. 